\title{
Social Credit System as a New Tool in the Management of Citizens' Behavior: Problems and Prospects
}

\author{
Rasim Mahammad Alguliyev, Irada Yavar Alakbarova \\ Institute of Information Technology of Azerbaijan National Academy of Sciences, Baku, Azerbaijan \\ E-mail: r.alguliev@gmail.com, airada.09@gmail.com
}

Received: 21 May 2021; Accepted: 12 September 2021; Published: 08 October 2021

\begin{abstract}
Due to the widespread use of modern information technologies in many countries, government agencies and individual companies are trying to assess the trust, reputation and behavior of citizens on the basis of personal data. Such assessment is called a social credit. Based on Chinese experience, this article identifies the impact of the Social Credit System (SCS) on the behavior of citizens and the problems that it poses in society. The purpose of the study is determine the importance of SCS in the formation of e-government. For this purpose, the principles of SCS "warning and punishment" were studied and key indicators used in the system were identified. Suggestions were developed to improve the effectiveness of SCS and prevent damage to the reputation of a law-abiding citizen by the system. The assessment of citizens on the basis of social credit allows you to get an information about not only the behavior of each person in the country, but also get an information about the general social situation in society. The presence in a society of a large number of citizens with a high credit rating can be an indicator of high quality of life in society. It can also be an indicator of the correct management of society and state.
\end{abstract}

Index Terms: Social credit, e-government, law-abiding citizen, principle of "warning and punishment", personal data, blacklisting, social credit scale, Sesame Credit.

\section{Introduction}

Throughout the history of modern society, various social groups, companies, and government agencies have evaluated people for different purposes. Hiring, establishing business, friendship or family relations, first of all, the reputation and trust of a person in society are taken into account. It is not easy to evaluate a person by his behavior, ability and reputation. Various statistical indicators and methods are used for the assessment. Regardless of the time, an individual's assessment primarily refers to a person's ability to work, education, marital status, interests, place of residence and the circle of people whom he communicates with, and so on.

With the development of information and communication technologies (ICT), people's activities have become more transparent, and the process of electronic management of society has expanded. The collection and analysis of personal data using ICT capabilities, the qualitative assessment of citizens without the participation of experts and using results in decision-making are currently very relevant. Various indicators are used to evaluate people depending on their purpose. The development of the information society and the impact of the global network on people's daily lives have led to a significant increase in the number of these indicators. The opinion about a specific person in society is based not only on his behavior and his work in real life, but also on his activity in the virtual space [1].

In a modern society where e-government are developing, various registers, banking systems, personal records and archives usually store with big data. On a national scale, the effective use of these data in the modernization of administrative mechanisms can help to prevent possible socio-economic crises in the country, ensuring information security and economic development [2, 3]. One of the such mechanisms are the Social Credit System (SCS). Assessing citizens by trust, reputation and importance in society in order to increase the country's economic power, ensure information security and solve the problem of social inequality is a very important task facing every state. The assessment of citizens by their personal data is called social credit [3].

SCS is a large-scale project with a long-term perspective. SCS is a giant infrastructure of state supervision for effective management, monitoring and forecasting, which controls not only citizens, but also organizations, companies and government agencies based on big data [4]. The system covers all areas, from financial loans, food safety to environmental safety $[5,6]$.

The purpose of the study is to identify the possibilities and role of social credit in the formation of e-government, as well as to identify existing problems in connection with the use of pilot SCS. For this purpose, the general principles 
and directions of SCS applied in China were investigated, as well as the "warnings and fines" used in the system of rules for the behavior of citizens were analyzed. Due to the fact that in China various studies are being carried out in the field of SCS and different versions of this system have been tested in different regions of the country, the authors decided to present the experience of China.

In this article, the authors have identified the main problems and advantages of SCS in China. For the efficient operation of the system without prejudice to civil rights, the authors developed new rules for SCS. To determine the quality of society, it was proposed to use the social credit scale.

\section{Chinese Experience in Social Credit Assessment}

Today, developed banking systems, insurance companies, state security bodies, for the effective management of the state, and the solution of socio-economic and military issues, different analytical systems are applied that determine the social credit of citizens and companies, solve various complex problems in the socio-economic sphere. The People's Republic of China have conducted extensive research in this area. SCS is tested in various regions of the country [4]. SCS collects personal data from social networks, taking into account the activity of citizens in cyberspace, from government agencies, banks, production information systems and so on. The system determines the social credit of each citizen which is based on the processing of all data. The goal is "to build the right society in the state" by strengthening public control over citizens [5].

In the official documents of the People's Republic of China, the term "social credit" was first used in 2003. These documents contain the main reasons confirming the importance of implementing SCS in the country [6]. They are as follows:

- Lack of a nationwide and effective credit risk assessment system. For this reason, China is losing 600 billion yuan (88.58 billion US dollars) a year.

- Thousands of people die every year due to poor-quality food.

- Chinese products are considered the most low-quality in the world.

- Counterfeit production is increasing.

- With a population of 1.4 billion, it is becoming increasingly difficult to control bribery and bureaucracy in the country.

- Tax evasion and fraud are increasing. Contracts and agreements in the social and economic spheres are not being implemented properly.

In the early 2000s, the Chinese scientists proposed using the experience of the United States to create a rule of law in the country and solve socio-economic problems. US credit systems "Equifax" and "TransUnion" evaluate the activities of individuals and companies and identify risks in economic relations. The situation in social and economic management in China required a quick solution to the problem. With this in mind, in 2007, the State Council of the People's Republic of China prepared the first document on the establishment of a social credit system [7]. In the same year in some Chinese cities and towns started piloting social credit projects. These pilot projects are managed by the government or large companies having information systems with big data.

On July 14, 2014, based on pilot projects and trials, China developed the "Social Credit System Action Plan (2014-2020)" (State Council of 2014). The action plan describes the general aspects and boundaries of collecting and evaluating data for determining social credits. The plan covers social relations, political views and ideology law systems that go beyond the economic aspects of credit. The effective governing mechanism is the Joint Punishment System. Many participants, including the Central Bank of the People's Republic of China, various ministries, local authorities and private companies, began to create and implement their own SCS in accordance with the 2014 plan [7,8].

The SCS action plan states that assessment and control through the SCS will ensure the security of the state and lead to the development of a person's morale [9]. The main task of SCS is to control 4 zones:

1. Correctness in government affairs;

2. Confidence in business relations;

3. Unity in public relations;

4. Justice in court decisions.

SCS evaluates citizens for their personal data and behavior. SCS is not the first project to assess the Chinese citizens. On a national scale, China's government uses different approaches to monitor and evaluate citizens. For example, the models Hukou (household registration) [10] and Dang'an (personal archives) [11] were used to strengthen state control based on personal data of citizens.

Hukou mainly controls migration and it was designed to prevent the outflow of people from villages to cities. The system analyzes personal data (age, education, credit history, etc.) and decides whether a citizen can live in the city. The Dang'an model archives personal data (ID, employment, education, etc.). Only officials with special permission have 
access to get information. In recent years, with the development of information technology, China has switched to the use of more complex models, such as "Internet censorship" and "big data analytics" [7, 12].

\section{The principle of "Warning and Punishment" in the SCS System}

SCS accumulates information from the databases of various central and local government agencies in China into "black" and "red" lists. The all-China SCS platform is also joined by regional and municipal credit information exchange platforms established in the provinces and cities of China. The system of "warning and punishment", which is the main component of the SCS, implies the application of coordinated disciplinary and incentive measures against those who are included in the "black" and "red" lists of subjects by multiple agencies respectively.

Research shows that most people on the blacklist are people who have not paid their debts or have committed a traffic violation. Compared to a blacklist, a positive list, also known as a redlist, has a higher degree of uncertainty [13].

Video surveillance cameras also play a special role in redlisting or blacklisting people. Assessing the situation and identifying anomalies by observing the behavior of citizens in public places is a very complex process. Research in this area is continues. [14]

SCS, which is called the system of "warnings and punishments", is often criticized by a number of Western countries. The Western media formed the idea that SCS conducts an assessment of all China's citizens and it is responsible for punishing citizens for their behavior. They argue that the control of the system over the actions of people can lead to the suppression of democracy and use the personal data against citizens [11, 15].

Criticism of SCS is related to the fact that this approach affects all aspects of the personal life of citizens. However, the Chinese government claims that, despite the difficulties, SCS plays an important role in managing risks in the socioeconomic sphere and can be an important tool to ensure and maintain public safety. In every country, citizens want a stable and safe society. In this regard, SCS can guarantee the formation of an exemplary state of the law in the country, with a high degree of control over the activities of citizens, state bodies and various companies. SCS is the world's first national system assessment of social credit [16]. This system is also known as the first digital system of dictatorship [17].

It is no secret that SCS is aimed at monitoring the activities of citizens and companies. Through SCS, the government encourages citizens and companies to behave in accordance with state policy and punish them for misconduct. In China, the use of surveillance devices, face recognition systems and biological identifications, as well as social networks to obtain accurate information about each citizen is not hidden by the authorities and calls this approach an important step in the formation of e-government by increasing the number of law-abiding citizens in the country [12, $15,17]$.

A law-abiding citizen is a person who reflects the qualities that every government wants to see in its citizens. The activities of friends and immediate family members also affect the social credit of every citizen. For example, if a close friend or brother said something against the government, this will reduce a person's social credit [18]. Rational thinking is essential when shopping. Since the purchase of a particular product gives information about the emotional state of a person [19].

Assessing social credit through SCS affects many aspects of Chinese life. You can get a well-paid job, a bank loan at low-interest rates and on favorable terms, study at a prestigious educational institution, etc. only for those with high social credit [16]. Using special methods and algorithms, SCS makes decisions about the enterprise, insurance program, vacation spot and even what kind of transport a citizen should use [20]. For example, a citizen with low social credit will be blacklisting. For a blacklisting citizen, it is forbidden to work in public institutions or even use certain vehicles (airplanes, high-speed trains) [21]. Actions such as traffic violations, smoking in public places, buying several video games, distributing false and anti-state messages on social networks can lead to a sharp reduction in social credit and blacklisting citizens. And if SCS shows high social credit, then he/she can afford to rent a car or a house without a deposit, get a well-paid job, etc.

SCS works in connection with judicial systems. In the past, debtors and scammers in China often failed to comply with court orders. The decisions remained on paper and after some time these people set up companies again, were engaged in business, received loans or had the opportunity to engage in illegal activities. This situation is badly influenced on the authority of the court. Corruption and low-quality production grew in the country. Starting in 2013, the names of those who were prosecuted by the court were included in the blacklist and their activities were limited [22].

In 2013, the government decided to create a blacklist to publish the name of those whom the system rated as an unreliable citizen [23]. In September 2016 the Chinese government developed a new version of the list of sanctions for people with low levels of social credit [24]. Despite various goals and applications, the principle of "warning and punishment" is the same for all systems. As a fine, it is known that restrictions affect the following areas [22, 23]: insurance, credit, or social security;

- Buying expensive items;

- Visiting expensive restaurants and hotels;

- Visiting foreign countries; 
- Education at prestigious schools and universities;

- The use of high-speed trains and aircraft;

- Work in government, law and journalism, food and pharmaceutical industries;

- Use of internet services.

In the April 2019, Hong Kong newspaper 'South China Morning Post' reported that China's National Development and Reform Commission, based on a social credit assessment, classified 13.49 million Chinese citizens as unreliable [25]

The SCS automatically determines which individuals and organizations will be punished for violating rules and regulations by applying the "blacklist". Punishment under the "blacklist" is carried out by various state bodies. For example, the Supreme People's Court of the People's Republic of China sends "blacklists" to individual ministries (education, culture, transportation, etc.) that punish citizens or companies within their powers. [26] Economic status of individuals, but also accuracy, sincerity and trust of companies and organizations, bureaucratic obstacles and delays in a state organization can lead to a punishment of the organization and blacklisting of its leaders. Fines imposed on organizations and companies include [27] :

- Tax increase;

- License revocation;

- Decrease in the probability of obtaining government contracts;

- Suspension from state-funded projects, etc.

In the SCS system, the principle of "warning and punishment" is simple: "If trust is violated in one area, restrictions apply to all areas" [28]. If any company failed to fulfill its obligations on time or if they are fined and punished by court order, the company's top management will be blacklisting by SCS. That is, they are subject of a number of restrictions.

The SCS documents say that for the system to work effectively, government agencies can use financial, legal and other data to evaluate citizens and all organizations operating in China and have the right to punish individuals and organizations with insufficient social credit.

\section{General Scheme of Social Credit Assessment}

In recent years, SCS has attracted a great deal of interest in sociology, law and ICT studies. These studies compare China's social credit system with US credit services, highlighting its advantages and disadvantages [29]. It also investigates how citizens' personal lives, work activities and behaviors in society impact these parameters on social credit, negative situations and their role in society are studied [30,31], such as the fact that SCS causes segregation of citizens, make it impossible for equal access to social services and benefits of the state [32].

Began experimenting with an SCS, which was tested by local authorities in 2010, Suining county, Jiangsu, initially give 1,000 points to all citizens. Points began to increase or decrease depending on the behavior of citizens [28]. For example, while an exemplary employee was rewarded with 30 or 50 points, a citizen could be fined 20 points for violating traffic rules, and 50 points for non-payment of a debt to a bank [30]. The system divides citizens into 4 categories: A, B, C and D. Citizens with credit points of 960 and higher belong to category A. Citizens with points $850-$ 959 belong to category B; 600-849 belong to C. Those citizens who have 599 points or less are considered unreliable and belong to category D. SCS does not take into account situations that can interfere with normal human activity (natural phenomena, diseases, etc.). For the categorization of citizens and since the system has no law basis for punishing citizens, it is often criticized in the media. Many local governments in China are also building their own municipal SCS. These systems are not very different from each other. Their main goal is to analyze the behavior and evaluate citizens, identify reliable and unreliable [33].

SCS consists of subsystems with various functions. Some of the subsystems collect and systematize information which stored in the archives of executive authorities and banking systems. Other subsystems are specific technical platforms that process the personal data of citizens [33].

In 2006, the People's Bank of China established the Credit Reference Center information system. The purpose of the system creation was to keep control of more than 500 million non-credit citizens by turning them into their customers. The program compiles credit reports based on information from banks and government agencies. In the June 2019, the system received information about 990 million citizens and 26 million companies [32].

Researchers believe that SCS is not only a monolithic monitoring and evaluation system controlled by the Chinese government, but also a set of distinct and fragmented systems and policies established by different centers and local governments, as well as private companies [ $34,35,36]$.

Chinese authorities report that, as a result of SCS tests, the assessment of social credit significantly increased the number of responsible citizens $[34,35]$. In their opinion, citizens who are trying to increase their social credit will be more diligent in their behavior and will try to be more accurate in their work, in the virtual space and various types of 
payments and avoid mistakes. Reports on the work of SCS say that the system collects data not only from different information systems, but also from social networks, Internet browsing history and online transactions, linking commercial paid platforms with government systems. One such system is "Sesame Credit".

One of the largest companies in the world, Alibaba, is in the forefront in the use of modern information technologies and has an intelligent information system (Sesame Credit), which provides SCS infrastructure [37]. Sesame Credit is very important in managing human resources when evaluating citizens based on personal data. The system is tested by Alibaba and, in addition to its own data, used data from other large Chinese companies, banking and insurance offices. As well as data from WeChat. The system, which leverages "big data" technology has collected data covering about half a billion Chinese citizens. Sesame Credit assigns 350 to 950 points to Alibaba users. Customers with good points receive special privileges on Alipay platform and partner platforms. The social credit is calculated using five different factors: credit history, behavior and preference, ability to fulfill obligations, personal characteristics, interpersonal relationships [37].

WeChat, owned by Tencent's largest Chinese social network, works in real-time, tracking the geographic location and behavior of citizens. Personal information obtained through WeChat is also collected and processed by Sesame Credit. The system estimates citizens at 350-950 points. How social credit is evaluated and which algorithms is used in the system are kept secret [22, 34]. However, Sesame Credit is open and allows citizens to access their credit information and use it for various assessments. Some cities in China began to independently create pilot SCS. In some of these systems, the scoring scale ranges from 0 to 200, and in some scoring scale from 0 to 1000 . After several unsuccessful attempts, in 2018, under the leadership of the People's Bank of China, SCS was created: Baihang Credit. Baihang is the only commercial rating agency licensed to issue credit reports to individuals. In 2019, the number of his clients is about 70 thousand people. The shareholders of Baihang Credit are such gigantic systems as the National Internet Finance Association, Tencent Credit, Sesame Credit, Qianhai Credit, Kaola Credit, etc. [30].

Social credit systems tested in China can be classified as follows:

1. SCS tested by the People's Bank of China.

2. SCS relating to local authorities and specific areas.

3. Sesame Credit tested by Alibaba.

Approaches for assessing social credit of citizens can be different:

- assessment as a law-abiding citizen;

- assessment as an important employee for the enterprise;

- assessment of his reputation in society;

- assessment of activities in social networks;

- assessment of attitude to nature and the environment.

There is no existing unified SCS in China. No central repository for receiving, managing, aggregation and analyzing the big data for. The lack of a single algorithm for assessing social credit and basic data sharing is one of the important problems on the way to creating a single SCS. But preparations are underway to build a unified credit system. In the unified credit system, data will be collected from three sources: People's Bank of China, Pilot projects of management organizations in China and Sesame Credit.

Official documents on SCS confirm that the necessary data on citizens and companies for assessing social credit can be collected from all possible sources [35]. This data is collected from the next 5 sources (fig. 1) [36, 37]:

1. Administrative sphere: marital status, tax, court documents, driving habits, etc.

2. Personal data: name, age, gender, speciality, email address, phone, place of residence, friends, etc.

3. Business sphere: information on insurance and data on consumers, payments, travel, telecommunications, credit history, bank accounts at the workplace, illegal activities, obligations, contracts.

4. Organization data: the behavior of personnel and management, compliance with safety standards at the workplace, compliance with state laws, compliance with social obligations, product quality, investment in research and development, environmental crimes.

5. Webspace: behavior on social platforms, virtual friends, social networks, comments and much more. 


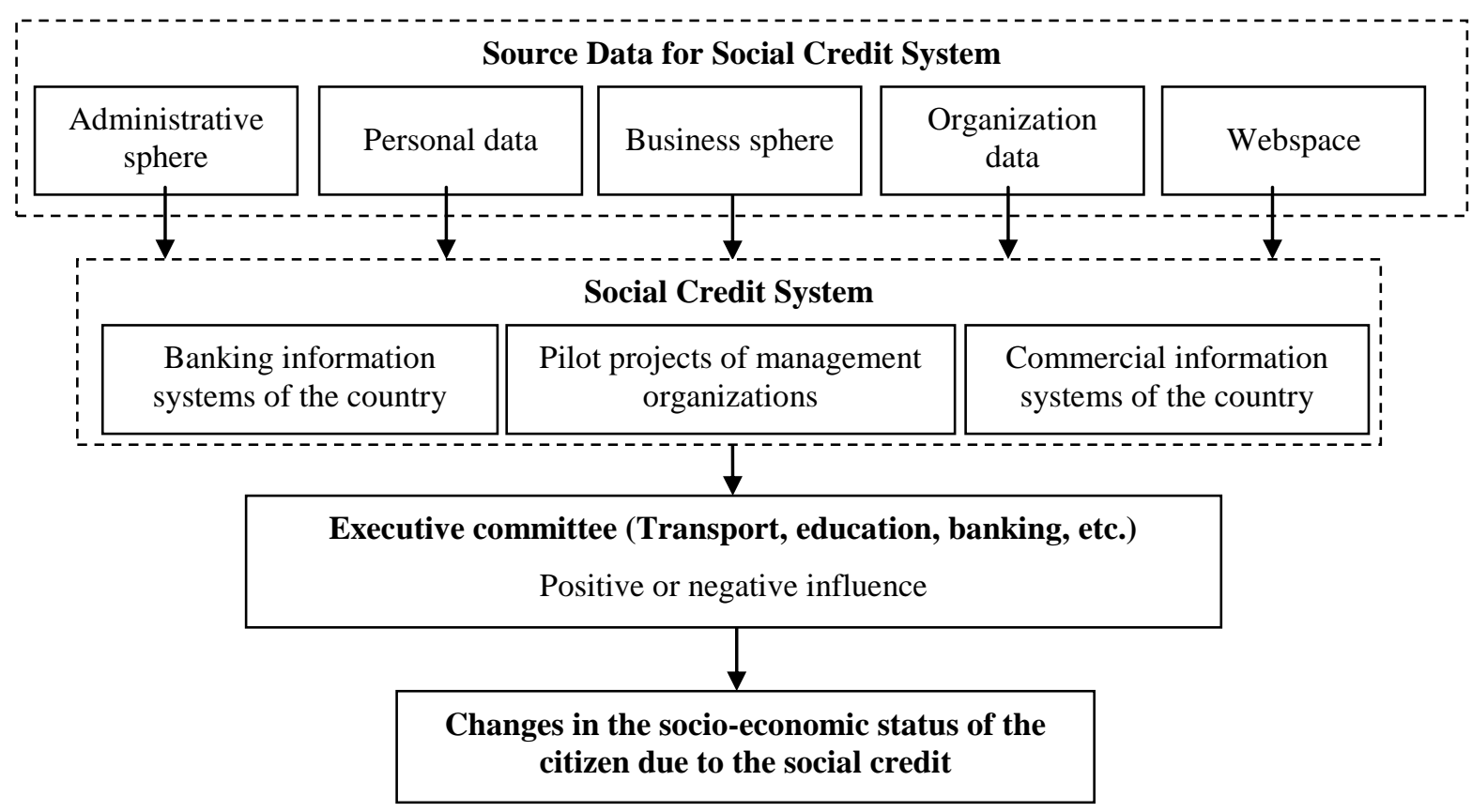

Fig. 1. General scheme of assessment of social credit for citizens

SCS mainly consists of 3 subsystems: Banking information systems, pilot projects of management organizations and commercial information systems. Banking information systems and commercial information systems collect and analyze all personal data of citizens, including demographics, credit history, social capital, and based on the results obtained, the executive committee determines the social credit of the citizen. Social credit for a citizen is an indicator of his socio-economic status.

A unified credit system in the country is very important for a quick and accurate definition of social credit. The following are the main benefits that the government can get as a result of evaluating social credit:

1. Identification of law-abiding citizens or blacklisting individuals as a result of their behavioral assessment;

2. Elimination of bureaucracy, fraud and bribery in the country as a result of evaluating social credit for government organizations and various companies.

The indicators used in the SCS can be divided into 2 groups depending on their purpose:

1. Direct indicators (quantitative indicators). These include indicators that are easily measurable and fairly objective. These indicators are always predetermined and determine the degree to which they should be achieved. For example, credit history, education, medical information and etc. indicators of citizen.

2. Indicators that indirectly affect the result. Indicators of this type cannot be accurately measured. For example, indicators such as a citizen's relationship with family members or his role in protecting the environment are vague and there is no reliable information about the impact on the result.

Social credit research can be classified in two ways: traditional approaches to credit theory and experimental methods. The first approach is based on various economic theories, such as institutional economics, information economics and game theory. Examples of experimental methods are multi-agent models, system dynamics and various simulation models [38].

The use of forecasting methods is very important in assessing social credit. Such an approach can help prevent social and economic risks that may pose a threat to society in the future. Forecasting methods can be divided into 4 groups: expert systems, traditional economic models, artificial intelligence and hybrid models [39, 40].

\section{Current Problems in the Social Credit System}

Studies have shown that the Chinese government handles all personal data on citizens by handing them over to SCS, and the identified social credit is publicly published in the national database. Social credit penalties pose serious problems in China regarding civil rights.

A. The main problems with the application of SCS:

1. The application of SCS is a tool to punish citizens. Any law-abiding citizen may fall victim to the principle of "warning and punishment" applied by the system for any error in conduct. 
2. Centralized management issue is still remains unresolved. To create a secure centralized database, data collection must come from all possible sources. And to solve this problem, all commercial firms must transfer the personal data of their customers to a centralized database. But not all corporations are willing to accept these conditions.

3. There is a possibility of bias against any citizen by a group or individual through SCS. For example, if a company manager deliberately gives negative feedback on employee's work and credibility, this could lead to a decrease in social security for both the employee and his or her family.

4. Social credit of citizens depends directly on the data collected in the system and the algorithms applied. It is not known what particular sources of data constituting the "big data" are used and there is no transparency in the algorithms using.

5. As with any information system, there are likely to be errors in the algorithms used in SCS.

6. The system administrator can influence the result by changing the structure and algorithm of the data in the system.

It is doubtful that there are legal grounds for penalizing citizens by the authorities and certain companies (banks, insurance, transport, medicine, education, etc.) for social credit. The inconsistency between the SCS case and the "warnings and penalties" principle with state laws creates problems.

\section{B. The law problems of SCS:}

1. Interference with the privacy of citizens through SCS, making their socio-economic situation dependent on information systems is contrary to democratic values and the principles of "personal data security".

2. Legal documents do not contain accurate information on the existence of national appraisal agencies and there are no regulatory provisions in the evaluation agencies.

3. The warning and punishment principle set out by the SCS is not reflected in the legal documents of the state. The legislation does not specify the definition of a social loan.

4. New approaches in punishing citizens of the country using SCS are not implemented under the law.

5. The Chinese authorities, who state the importance of SCS, do not address the importance of protecting the personal information of citizens.

6. China, by law, does not have the right to mass surveillance of citizens, as well as to the collection and processing of all personal data by private companies and government agencies.

If the assessment of social credit does not satisfy the citizen or the citizen wants to have an idea of how this assessment was obtained, the question arises: where do the dissatisfied citizens turn to? Social credit has a serious impact not only on the citizen but also on the family and socio-economic life of their children. From this, we can conclude that thanks to the SCS, the government can guide and shape the behavior of citizens in the direction they need. In addition, since the algorithms are not made public, ethnic groups, religious and national minorities run the risk of suffering from this system.

Studies have shown that the main dissatisfaction with the work of SCS is that it does not take into account the circumstances during the incident. Some circumstances in the behavior of citizens are presented in the following examples:

- as a result of an incorrect search on the Internet, the receipt and transmission of information that is not supported by the state;

- neglect of citizens' health problems. For example, a patient falling on the street looks like he is drunk on a surveillance camera and so on.

- incorrect information on the behavior of a citizen as a result of an unexpected event or psychological situation. For example, if citizen uses a stick to protect himself from street dogs, then the system may consider this as aggression against animals.

\section{The situation with operating systems}

The reliability of the operating system (OS) is the most important expectation for the efficient operation of the SCS, since the OS is the intermediary and controller of the system's security. Achieving the reliability of SCS requires higher quality standards in several aspects. Typically, more emphasis is placed on security techniques to detect vulnerabilities faster and then prevent them before any exploitation occurs. This task is mandatory and important. However, while these qualitative measures are taken, it is also important to consider the risk associated with vulnerabilities in computer systems [41].

Potentially dangerous situations in operating systems are as follows:

- Lack of transparency in data sources and algorithms used in processing SCS data is the reason for the distrust of some countries in the system; 
- The probability of system errors caused by processing too much data;

- Errors caused by the carelessness of the system operator;

- The inaccuracy of information entered into the system and technical errors in the algorithm.

Social credit should also take into account the environment, age and education of the citizen. For example, since a credit history of 16 or 20 years old does not correspond to a credit history of 40-60 years, the result of the algorithm may not be accurate.

\section{Suggestions}

Based on the indicators, the degree in which citizens may or may not meet the requirements established by the SCS is determined. While SCS defines the rating as "positive," the financial and socio-economic situation of citizens and companies is improving. This contributes to the growth of their reputation. A "negative" price can lead to the loss of social services, material resources, state support and loss of prestige. Taking into account SCS studies and existing problems, we can say that in order to increase the efficiency of SCS it is necessary to solve the following tasks:

1. To be informative. The citizen should be informed about what personal data are used and from which databases they are taken from when assessing social credit. SCS should clearly show for what behavior the citizen's social credit was reduced and increased.

2. There should be objectivity in the system. The assessment should not be based on any specific opinion or individual judgment. For example, if a neighbor does not like another neighbor, this should not affect the social credit of a law-abiding citizen who follows all the rules and social norms. Studies have shown that in order to achieve accurate results in assessing social credit, the data intended for analysis must be relevant, and the algorithms well-designed and flexible.

3. The rights of citizens must be taken into account. Legal documentation should contain accurate information on the existence of national valuation agencies. There should be regulatory conditions for evaluating social credit scores. If the citizen's activities are not illegal, he or she will be able to graduate, travel and so on. They should not be punished by prohibitions.

4. It is necessary to take into account situational effects (accidents, natural phenomena, etc.). For example, if a citizen's car is flooded or struck by lightning, it should be considered as a natural disaster, and not through the fault of the citizen.

5. The psychological situation should be taken into account. Phobias of citizens against animals or insects, inability to social relations, etc., personal qualities should not be mentioned by the system as bad.

6. Children should not be responsible for the actions of parents. If due to the low social credit of the parent, the child cannot attend the school he wants, it is a tragedy of society.

7. The prestige of the citizen must be taken into account. Mass publication, names, that have been blacklisted should be carried out exclusively with the consent of these citizens.

The scope of the principle of "warning and punishment", used in SCS and tested in different regions of the country, has not been fully investigated. In order to present the actions of a citizen with low social credit as a violation of the law and punish him for it, such a right must first be reflected in legal documents. For this reason, the integration of SCS into public administration will become possible only after a comprehensive review of the legal concept in the state. New approaches to the punishment of citizens by SCS should be implemented within the framework of the law. Thus, if the principle of "warning and punishment" established by the system is not reflected in the legal documents of the state, fines for social loans should be considered illegal.

Methods for assessing social credit may be different:

- assessment as a law-abiding citizen;

- assessment as an important employee;

- assessment of the reputation of a citizen in society;

- assessment of social relations;

- assessment of human attitudes towards nature and the environment.

A high level of social credit of citizens depends solely on their behavior in society and the virtual space. The level of a company's social credit depends on trust and responsibility. 


\section{Recommendations}

Assessment of social credit will lead to the predominance of law-abiding citizens in the community and, as a result, to improve the quality of society itself. Law-abiding and reliable citizens are the basis for economic and social wellbeing in the country. But it will also strengthen the state dictatorship and control over citizens.

Studies have shown that SCS is not always well received in the world and in this area there are two different points of view. These views are listed below:

1. At first glance, SCS is a system that contributes to the creation of the rule of law using a system of "warnings and punishments" which seeks to improve the well-being of citizens and support the formation of a large number of law-abiding citizens. SCS requires citizens to participate directly in maintaining socio-economic stability in the state.

2. According to the second opinion, SCS is a modern method of sanctions that supports government intervention in the privacy of citizens, contrary to the law, thereby violating the rights of citizens and ultimately not observing the laws of the state. The assessment of social credit for each citizen is made public and makes it impossible for people with low social credit to use the same level of social services and benefits. This leads to the stratification of society.

Studies have shown that SCS has a wide range of opportunities to enhance the role of a law-abiding citizen in public administration. Given that trust and prestige are the basis for the formation of a law-abiding citizen, we can confidently say that social credit is a guarantee of trust and prestige of a person in society. However, studies have also shown that China has not yet created a legal framework to meet SCS requirements.

Table 1. General conditions for the assessment of society on the social credit scale

\begin{tabular}{|c|l|}
\hline IQ & \multicolumn{1}{c|}{ Characteristics of society } \\
\hline++ & a society of law-abiding citizens with high social credit \\
\hline$+>-$ & a society in which the majority of citizens have high social credit (credit score of more than 600) \\
\hline$+=-$ & $\begin{array}{l}\text { society where the number of citizens with high social credit (credit score is more than 600) is equal to the number of citizens } \\
\text { with low social credit (credit score is less than 600) }\end{array}$ \\
\hline$+<-$ & a society in which most citizens have low social credit (credit score less than 600) \\
\hline-- & a society of citizens with low social credit (credit score less than 600) \\
\hline
\end{tabular}

As research shows, SCS contributes to increasing the number of law-abiding citizens with high IQ in society. And this is the main goal in the formation of e-government. To determine the quality of society, it is more appropriate to use the scale of social credit.

The social credit scale is shown in table 1 . The main purpose of applying the scale of social credit:

- It is important to identify law-abiding citizens in society, that is, a class that has high intelligence and knowledge, which does not go beyond legal and ethical standards.

- Using the scale of social credit, you can conduct a comparative analysis of the quality of society in various organizations, associations and even countries.

- The scale of social credit will determine not only the social status of the country, but also the quality of management.

Using the social credit scale, we can gain knowledge about the most important sections of society or citizens that are most important to the government and make the right decisions. We can even appreciate the socio-economic relations between social groups. It should be born in mind that a citizen can change his geographic location or business at certain intervals. In this situation, there is a high probability of certain behavioral errors. This will lead to a decrease in social credit citizens over a period of time. Increasing or decreasing social credit overtime is acceptable. The purpose of the social credit scale is not to punish low-income citizens, it is identify the causes of the decline and take alternative measures to address these causes, as well as create a rule of law state with most law-abiding citizens.

We believe that social credit issues in e-government should be organized in accordance with legal compliance. It must be clearly communicated to citizens what data are used in SCS and taken into account the opinions and problems of citizens associated with social lending. As a result of the impact of the system on the lives of citizens, citizen satisfaction should be assessed. Social credit should not be aimed at limiting the rights of citizens, its for increasing their social and economic potential. Such an approach can radically change social management in the country and lead to the creation of strong, modern e-government. 


\section{Conclusion}

Research has shown that while social credit settlement through SCS is designed to ensure the economic well-being and security of a country, it can tarnish citizens' rights, affect their lives, and create data security problems.

The collection and processing of information about a citizen by any company or government organization in the egovernment environment should be carried out within the framework of national and international laws adopted in this direction. If the processing and using personal data takes place under the protection of civil rights, this can be the basis for ensuring the integrity and transparency of a company or organization, trust and mutual understanding between the state and a citizen, an employee and an organization.

The study confirms the importance of processing personal data collected by various analytical systems into a single system and calculating social credit to ensure the socio-economic security of the state within the framework of adopted national and international laws.

Socio-economic problems that arise in society cannot be completely eliminated by special rules and measures adopted by the government. Each citizen has a number of responsibilities for managing e-government. To succeed in public administration, it is necessary to ensure effective interaction between government bodies and citizens. SCS should identify and encourage citizens who have never violated the law and have authority in society. The CSC trial in China is a unique attempt to automate social control and social management. However, SCS should help identify the reasons that impede the development of society and not punish citizens. In future studies, we will consider the function of SCS in supporting the activities of a law-abiding citizen, that is factors that can contribute to increasing the economic and social activity of citizens as a result of making the right decisions in managing e-government.

\section{References}

[1] M. Tsukamoto. Integrating real space and virtual space in the 'invisible person' communication support system. Proceedings of the $1^{\text {st }}$ International Conference on Advanced Multimedia Content Processing, Osaka, Japan, nov. 09-11, 1998, vol. 1554, pp. 59-74.

[2] R.M. Alguliyev, F.F. Yusifov. E-Government Formation Challenges and Solution Perspectives. E-Systems for the 21st Century, 2019, vol. 1: E-Commerce, E-Decision, E-Government, E-Health, and Social Networkspp, pp. 171-196.

[3] F.A.F Ferreira, J.P. Esperanca, M.A.S. Xavier, R.L.Costa, B. Perez-Gladish A socio-technical approach to the evaluation of social credit applications. Operational Research Society, 2019, vol. 70, Issue 10, pp. 1801-1816.

[4] G. Kostka. Antoine L. Fostering. Model Citizenship: Behavioral Responses to China's Emerging Social Credit Systems. Policy and Internet, 2019, https://papers.ssrn.com/sol3/papers.cfm?abstract_id=3305724

[5] J.Z. Yan. China's Social Credit System: A Primer. The Journal of International and Public Affairs, 2018, vol. 1, no. 1, https://www.jipasg.org/posts/2018/9/6/introduction-to-chinas-social-credit-system

[6] C. Hatton. China social credit: Beijing sets up huge system, 2015, http://www.bbc.com/news/world-asia-china-34592186

[7] Y. Chen, A.S.Y. Cheung. The Transparent Self Under Big Data Profiling: Privacy and Chinese Legislation on the Social Credit System. Comparative Law, 2017, vol. 12, no. 2, pp. 356-378.

[8] Chinese Social Credit System (I): what it is - and what it isn't, https://polikracia.com/the-chinese-social-credit-system/

[9] Planning Outline for the Construction of a Social Credit System (2014-2020), https://chinacopyrightandmedia.wordpress.com/2014/06/14/planning-outline-for-the-construction-of-a-social-credit-system2014-2020/

[10] K.W. Chan. The Household Registration System and Migrant Labor in China: Notes on a Debate // Population and Development Review, 2010, vol. 36, no. 2, pp. 357-364.

[11] W.W. Moss. Dang'an: Contemporary Chinese Archives // The China Quarterly, 1996, no. 145, pp. 112-129.

[12] B. Song. Opinion The West may be wrong about China's social credit system. The WorldPost, 2018, https://www.washingtonpost.com/news/theworldpost/wp/2018/11/29/social-credit

[13] N. Kshetri. China's Social Credit System: Data, Algorithms and Implications. IT Professional, 2020, vol. 22, no. 2, pp. 14-18.

[14] A.F.M. Saifuddin Saif, Sh. Akib, A. M. Hadi, R. P. Karmoker, J. J. Gomes. Aggressive Action Estimation: A Comprehensive Review on Neural Network Based Human Segmentation and Action Recognition. International Journal of Education and Management Engineering (IJJEME), vol. 9, no. 1, pp. 9-19

[15] F. Liang, V. Das, N. Kostyuk, M.M. Hussain. Constructing a Data Driven Society: China's Social Credit System as a State Surveillance Infrastructure. Policy and İnternet, 2018, https://onlinelibrary.wiley.com/doi/pdf/10.1002/poi3.183

[16] S. Engelmann, M. Chen, F. Fischer, CY. Kao, J. Grossklags. Clear Sanctions, Vague Rewards: How China's Social Credit System Currently Defines "Good" and "Bad" Behavior. Proceedings of the ACM Conference on Fairness, Accountability and Transparency, Atlanta, GA, USA, Jan. 29-31, 2019, pp. 69-78

[17] S. Triaria. Digital Dictatorship or Digital Republic? Law and Ethics of China's Social Credit System, Robert Schuman Centre for Advanced Studies, 2019,

[18] Leave no dark corner, https://www.abc.net.au/news/2018-09-18/china-social-credit-a-model-citizen-in-a-digitaldictatorship/10200278

[19] K.Senthilkumar. The Influence of Emotional Factors in the Purchase of Children Products and Brands, International Journal of Education and Management Engineering (IJEME), 2018, vol.8, no.5, pp.18-30. 
[20] A. Mortensen. The Chinese Social Credit System in the Context of Datafication and Privacy, 2018, https://medium.com/@alexanderskyummortensen/the-chinese-social-credit-system-in-the-context-of-datafication-and-privacycafc9bb7923b

[21] J.C. Hunter All data is credit data or on close reading as a reciprocal process in digital knowledge environments. Scholarly and Research Communication, 2014, vol. 5, no. 2, Online: http://src-online.ca/index.php/src/article/view/172/325

[22] Chinese courts to blacklist judgment defaulters, China Daily, July 19, 2013, on www.chinadaily.com.cn/china/201307/19/content_16803133.htm

[23] Ch.F. Shen. Social Credit System in China. The Konrad-Adenauer-Stiftung (Regional Programme Political Dialogue Asia/Singapore), 2019, 8 p., https://www.kas.de/en/web/politikdialog-asien/single-title/-/content/social-credit-system -in-china2

[24] M. Chorzempa, P. Triolo, S. Sacks. China's Social Credit System: A Mark of Progress or a Threat to Privacy? Policy Brief, 2018, 11 p. https://www.piie.com/system/files/documents/pb18-14.pdf

[25] China-Internal: Efficiency of Social Credit Mgt System, https://ccasindia.org/newsdetails.php?nid=3559

[26] T. Zhang, T. Ginsburg. Legality in Contemporary Chinese Politics. Virginia Journal of International Law, 2018, no. 657, 65 p.

[27] M. Blomberg. The Social Credit System and China's Rule of Law. Mapping China Journal, 2018, no. 2, pp. 77-162.

[28] Blacklists and redlists: How China's Social Credit System actually works, https://technode.com/2018/10/23/china-social-credit/

[29] S. Hoffman. Managing the State: Social Credit, Surveillance and the CCP's Plan for China. China Brief. 2017, vol. 17, issue 11, pp. 21-27.

[30] Report: Understanding China's Social Credit System, 2019, 58 p. http://socialcredit.triviumchina.com/wpcontent/uploads/2019/09/Understanding-Chinas-Social-Credit-System-Trivium-China-20190923.pdf

[31] G. Kostka. China's social credit systems and public opinion: Explaining high levels of approval // New Media \& Society, 2019, vol. 21, no. 7, pp. 1565-1593.

[32] J.X. Klein Why US businesses should be worried about China's corporate social credit system, 2019, https://www.scmp.com/news/china/article/3032720/why-us-businesses-should-be-worried-about-chinas-corporate-social-credit

[33] L. Chuncheng. Multiple Social Credit Systems in China. Economic Sociology: The European Electronic Newsletter, 2019 , vol. 21, no. 1, pp. 22-32.

[34] D.M. Síthigh, M. Siems. The Chinese social credit system: A model for other countries, European University Institute Department of Law, 2019, 39 p.

[35] Y. Lei. Beyond the Rule of Law: Rule-based Regulation under the Social Trustworthiness System. Central South University (Social Science Edition), 2014, no. 4, pp. 65-72.

[36] Ant Financial Unveils China's First Credit-Scoring System Using Online Data, 2018, https://www.alibabagroup.com/en/news/article?news=p150128

[37] Sh. Ahmed Cashless Society, Cached DataSecurity Considerations for a Chinese Social Credit System, January 24,2017 https://citizenlab.ca/2017/01/cashless-society-cached-data-security-considerations-chinese-social-credit-system/

[38] L. Yu, X. Li, L. Tang, Z. Zhang, G. Kou. Social credit: a comprehensive literature review. Financial Innovation, 2015, vol. 1, no. 6, pp. 2-18.

[39] A. Blanco, R. Pino-MejíAs, J. Lara, S. Rayo. Credit scoring models for the microfinance industry using neural networks: evidence from Peru. Expert Systems with Applications, 2012, vol.40, no. 1, pp. 356-364.

[40] J. Yim, H. Mitchell Comparison of country risk models: hybrid neural networks, logit models, discriminant analysis and cluster techniques. Expert Systems with Applications, 2005, vol. 28, no. 1, pp. 137-148.

[41] P.K. Kaluarachchi, C. Attanayake, S. Rajasooriya, Ch.P. Tsokos. An Analytical Approach to Assess and Compare the Vulnerability Risk of Operating Systems // International Journal of Computer Network and Information Security (IJJCNIS), 2020, vol. 12, no. 2, pp. 1-10.

\section{Authors' Profiles}

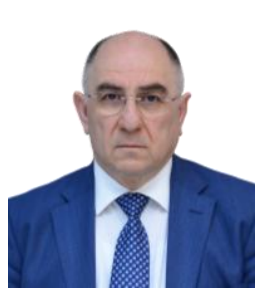

Rasim Mahammad Alguliyev is director of the Institute of Information Technologies of Azerbaijan National Academy of Sciences (ANAS) and vice-president of it. He is full member of ANAS and full professor. He received BSc and MSc in electronic computing machines from the Azerbaijan Technical University in 1979. He received his Ph.D. and Doctor of Science (higher degree after Ph.D.) in Computer Science in 1995 and 2003, respectively. His research interests are: Information Security, Information Society, Online Social Network Analysis, Cloud Computing, Evolutionary and Swarm Optimization, Data Mining, Social Network Analysis, Big Data Analytics, and Scientometrics. He is the author of more than 600 papers, four monographs, four patents and several books.

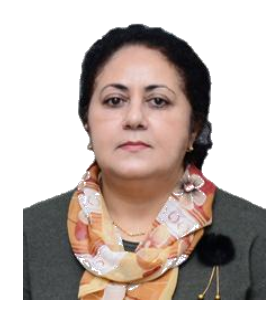

Irada Yavar Alakbarova in 1984 she graduated from the Faculty of Automation of production processes, Azerbaijan Institute of Oil and Chemistry named after M. Azizbayov. In the same year, she was accepted for employment at the Institute of Information Technology of the ANAS. In currently holds the post of Sector Chief of the Institute of Information Technology of ANAS. In 2018, the defense of the dissertation on the "Development of methods and algorithms for analysis of information war technologies in a wiki environment" and she received his Ph.D. (2018). In currently conducts research in the field of Social Network Analysis, Text Analysis, Clustering, Social Credit Analysis, and Big Data Analytics. She is the author of 45 articles and three books. 
How to cite this paper: Rasim Mahammad Alguliyev, Irada Yavar Alakbarova, " Social Credit System as a New Tool in the Management of Citizens' Behavior: Problems and Prospects", International Journal of Education and Management Engineering (IJEME), Vol.11, No.5, pp. 1-12, 2021. DOI: 10.5815/ijeme.2021.05.01 